\title{
Lubrication Oil Condition Monitoring and Remaining Useful Life Prediction with Particle Filtering
}

\author{
Junda Zhu ${ }^{1}$, Jae M. Yoon ${ }^{1}$, David $\mathrm{He}^{1}$, Yongzhi $\mathrm{Qu}^{1}$, and Eric Bechhoefer ${ }^{2}$ \\ ${ }^{1}$ Department of Mechanical and Industrial Engineering, The University of Illinois at Chicago, Chicago, IL, 60607, USA \\ davidhe@uic.edu \\ ${ }^{2}$ NRG Systems, Hinesburg, VT, 05461, USA \\ erb@nrgsystems.com
}

\begin{abstract}
In order to reduce the costs of wind energy, it is necessary to improve the wind turbine availability and reduce the operational and maintenance costs. The reliability and availability of a functioning wind turbine depend largely on the protective properties of the lubrication oil for its drive train subassemblies such as the gearbox and means for lubrication oil condition monitoring and degradation detection. The wind industry currently uses lubrication oil analysis for detecting gearbox and bearing wear but cannot detect the functional failures of the lubrication oils. The main purpose of lubrication oil condition monitoring and degradation detection is to determine whether the oils have deteriorated to such a degree that they no longer fulfill their functions. This paper describes a research on developing online lubrication oil condition monitoring and remaining useful life prediction using particle filtering technique and commercially available online sensors. It first introduces the lubrication oil condition monitoring and degradation detection for wind turbines. Viscosity and dielectric constant are selected as the performance parameters to model the degradation of lubricants. In particular, the lubricant performance evaluation and remaining useful life prediction of degraded lubrication oil with viscosity and dielectric constant data using particle filtering are presented. A simulation study based on lab verified models is provided to demonstrate the effectiveness of the developed technique.
\end{abstract}

\section{INTRODUCTION}

Lubrication oil is an important information source for early machine failure detection just like the role of the human blood sample testing in order to perform disease detection. In modern industries, lubrication oil plays a critical part in

Junda Zhu et al. This is an open-access article distributed under the terms of the Creative Commons Attribution 3.0 United States License, which permits unrestricted use, distribution, and reproduction in any medium, provided the original author and source are credited. condition maintenance of complicated machineries such as wind turbines. In recent years, health condition monitoring and prognostics of lubrication oil has become a significant topic among academia and industry. Significant effort has been put into oil diagnostic and prognostic system development and research. In comparison with vibration based machine health monitoring techniques, lubrication oil condition monitoring provides approximately 10 times earlier warnings for machine malfunction and failure (Poley, 2012). The purpose of most research is, by means of monitoring the oil degradation process, to provide early warning of machine failure and most importantly extend the operational duration of lubrication oil in order to reduce the frequency of oil changes and therefore reduce maintenance costs.

For the wind industry, in order to reduce wind energy costs, there is a pressing need to improve the wind turbine availability and reduce the operational and maintenance costs. The reliability and availability of a functioning wind turbine depends largely on the protective properties of the lubrication oil for its drive train subassemblies such as gearbox and means for lubrication oil condition monitoring and degradation detection. The wind industry mostly uses offsite lubrication oil analysis. The lubrication oil in the wind turbine is normally sampled every 6 months and sent to oil analysis labs for feedback on the condition of the oil. However, the online health monitoring of functional failures of lubrication oil has been an issue that cannot be handled by such techniques and remains to be an unsolved problem. The purpose of lubrication oil condition monitoring and degradation detection is to determine whether the oil has deteriorated to such a degree that it no longer fulfills its protective function and to provide early warning of the possibility of total failure. As stated by Sharman and Gandhi (2008), and many other researchers, the primary function of lubrication oil is to provide a continuous layer of film between surfaces in relative motion to reduce friction and 


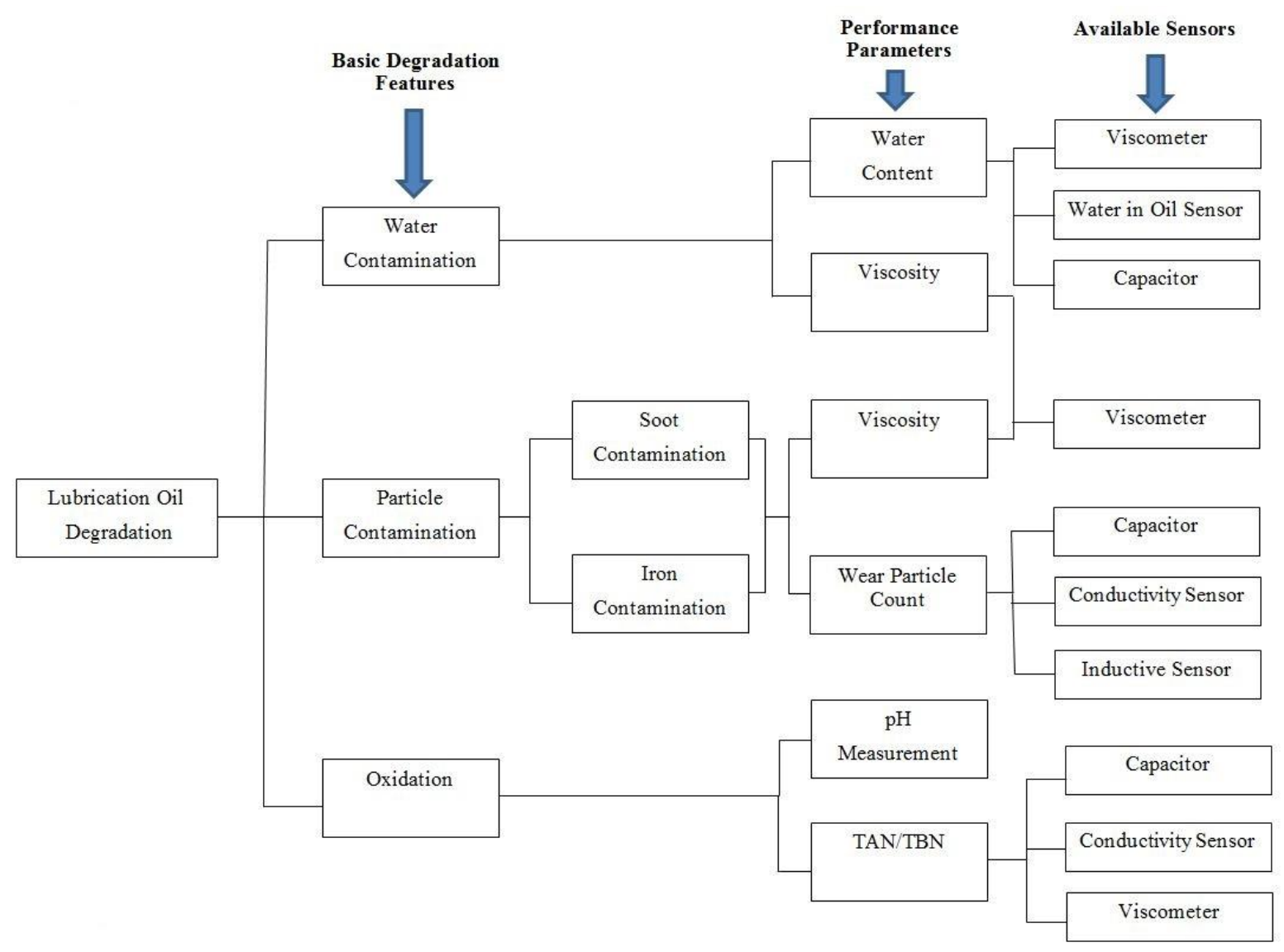

Figure 1. The relationship among the basic degradation features, performance parameters, and available oil condition sensors

prevent wear, and thereby, prevent seizure of the mating parts.

The secondary function is to cool the working parts, protect metal surfaces against corrosion, flush away or prevent ingress of contaminants and keep the mating component reasonably free of deposits. In a lubricated system, variation in physical, chemical, electrical (magnetic) and optical properties change the characteristics of the lubrication oil and lead to the degradation as its protective properties. The main causes of turbine lubricant deterioration are oxidation, particle contamination, and water contamination. These three are defined in this paper as lubrication oil basic degradation features. The parameters that describe the lubrication oil performance or level of degradation are called performance parameters. These parameters include viscosity, water content, total acid number (TAN), total base number (TBN), particle counting, $\mathrm{pH}$ value and so forth. Each performance parameter can be measured by certain sensing techniques. The relationship among the basic degradation features, performance parameters, and available oil condition sensors is shown in Fig. 1. Also, Table 1 shows the performance parameters for different kinds of applications and their benchmark for lubrication oil degradation. For example, for water content, it measures the water contamination percentage of the lubrication oil. This performance parameter is necessary and crucial to gearbox, hydraulic system, engine, compressor and turbine applications. Water content can be measured by a capacitance sensor, viscosity sensor, and water in oil sensor.

To find a feasible solution for online lubrication oil health condition monitoring and remaining useful life (RUL) prediction, it is necessary to conduct a comprehensive review of the current oil health monitoring techniques. The investigation on current state of the art lubrication oil monitoring techniques is reported in (Zhu et al., 2012; 2013). Over the years, scientists and experts have developed sensors and systems to monitor one or more of the lubrication oil performance parameters in order to monitor the oil condition effectively. These sensors and systems can be summarized into four categories including electrical (magnetic), physical, chemical, and optical techniques. For example, the most effective electrical technique for oil health monitoring is detecting the dielectric constant change of the lubrication oil. According to recent studies, the 


\begin{tabular}{|c|c|c|c|c|c|c|c|c|c|}
\hline \multirow{2}{*}{$\begin{array}{l}\text { Performance } \\
\text { Parameters }\end{array}$} & \multirow{2}{*}{$\begin{array}{l}\text { Measurement } \\
\text { Function }\end{array}$} & \multirow{2}{*}{ Unit } & \multirow{2}{*}{$\begin{array}{c}\text { Benchmark } \\
\text { of } \\
\text { Degradation }\end{array} \mid$} & \multicolumn{5}{|c|}{ Applications } & \multirow{2}{*}{$\begin{array}{c}\text { Available Measurement } \\
\text { Approach }\end{array}$} \\
\hline & & & & $\begin{array}{l}\text { Gear } \\
\text { box }\end{array}$ & $\begin{array}{l}\text { Hydraulic } \\
\text { system }\end{array}$ & Engine & Compressor & Turbine & \\
\hline $\begin{array}{l}\text { Viscosity }(40 \\
\left.{ }^{\circ} \mathrm{C}\right)\end{array}$ & \multirow{2}{*}{$\begin{array}{l}\text { Contamination } \\
\text { of lubricant by } \\
\text { some other oil, } \\
\text { oxidation }\end{array}$} & \multirow{2}{*}{$\begin{array}{c}\text { Cst } \\
\left(\mathrm{mm}^{2} / \mathrm{s}\right)\end{array}$} & $\begin{array}{l}\geq 55 \\
\leq 50\end{array}$ & \multirow{2}{*}{ yes } & \multirow{2}{*}{ yes } & \multirow{2}{*}{ yes } & \multirow{2}{*}{ yes } & \multirow{2}{*}{ yes } & Kinetic Viscometer \\
\hline $\begin{array}{l}\text { Viscosity }(100 \\
\left.{ }^{\circ} \mathrm{C}\right)\end{array}$ & & & $\begin{array}{l}\geq 10 \\
\leq 8\end{array}$ & & & & & & $\begin{array}{l}\text { Micro-acoustic } \\
\text { Viscometer }\end{array}$ \\
\hline \multirow{3}{*}{ Water Content } & \multirow{3}{*}{$\begin{array}{l}\text { Presence of } \\
\text { water }\end{array}$} & \multirow{3}{*}{$\%$} & \multirow{3}{*}{$\leq 2$} & \multirow{3}{*}{ yes } & \multirow{3}{*}{ yes } & \multirow{3}{*}{ yes } & \multirow{3}{*}{ yes } & \multirow{3}{*}{ yes } & $\begin{array}{l}\text { Capacitance sensor } \\
\text { (Dielectric constant) }\end{array}$ \\
\hline & & & & & & & & & Kinetic Viscometer \\
\hline & & & & & & & & & Water in oil sensor \\
\hline \multirow{3}{*}{ TAN/TBN } & \multirow{3}{*}{$\begin{array}{l}\text { Acidity/alkalini } \\
\text { ty of lubricant } \\
\text { (oxidation } \\
\text { level) }\end{array}$} & \multirow{3}{*}{$\underset{\mathrm{gm}}{\mathrm{mgKOH} /}$} & \multirow{3}{*}{$\begin{array}{l}\geq 0.6 \\
\leq 0.05\end{array}$} & \multirow{3}{*}{ yes } & \multirow{3}{*}{ yes } & \multirow{3}{*}{ yes } & \multirow{3}{*}{ yes } & \multirow{3}{*}{ yes } & $\begin{array}{l}\text { Capacitance sensor } \\
\text { (Dielectric constant) }\end{array}$ \\
\hline & & & & & & & & & Kinetic Viscometer \\
\hline & & & & & & & & & Conductivity Sensor \\
\hline Flash point & $\begin{array}{l}\text { Presence of } \\
\text { dissolved } \\
\text { solvents or } \\
\text { gases in the } \\
\text { lubricant }\end{array}$ & ${ }^{\circ} \mathrm{C}$ & $\begin{array}{l}\geq 220 \\
\leq 140\end{array}$ & no & yes & yes & no & no & Thermometer \\
\hline $\begin{array}{l}\text { Wear Particle } \\
\text { Count }\end{array}$ & $\begin{array}{l}\text { Wear particles } \\
\text { in parts per } \\
\text { million }\end{array}$ & ppm & $\leq 40$ & yes & yes & yes & yes & yes & $\begin{array}{l}\text { Capacitance sensor } \\
\text { (Dielectric constant), }\end{array}$ \\
\hline $\begin{array}{l}\text { Particle } \\
\text { Counting }\end{array}$ & $\begin{array}{l}\text { Detect number } \\
\text { of particles for } \\
\text { sample size of } \\
100 \mathrm{cc}\end{array}$ & $\mathrm{mg} / \mathrm{L}$ & $\leq 200$ & no & yes & no & no & yes & $\begin{array}{l}\text { Kinetic Viscometer, } \\
\text { Conductivity Sensor, } \\
\text { Inductive Sensor }\end{array}$ \\
\hline
\end{tabular}

Table 1. Performance parameters, applications and their benchmark for lubrication oil degradation.

capacitance or permittivity change can be used to monitor the oxidation, water contamination, and wear particle concentration. On the other hand, for physical techniques, viscosity is commonly discussed. The lubrication oil oxidation, water contamination, particle concentration, and some other property changes all have an influence on oil viscosity. Therefore, viscosity is considered an objective mean of oil degradation detection. The final goal of all above mentioned systems is to achieve lubrication oil online health monitoring and remaining useful life prediction in industrial machineries. Note, that most sensing systems are only capable of off-line monitoring, in which oil samples are collected from the machinery by specialists and sent to laboratories for oil condition analysis. In this way, the actual condition of the lubrication oil cannot be determined online because of the sampling and analysis delay. With the deployment of online oil condition monitoring techniques, one can optimize the maintenance schedule and reduce the maintenance costs.
In this paper, based on the previous results of a comprehensive investigation of oil condition monitoring techniques reported in (Zhu et al., 2012; 2013), the two most effective online lubrication oil sensors, kinematic viscometer and dielectric constant sensors, are selected to develop an online lubrication oil health monitoring and remaining useful life prediction tool. Kinematic viscosity is the absolute viscosity with respect to liquid density while dielectric constant is the relative permittivity between the lubrication oil and air.

The purpose of this paper is to present the development of an online lubrication oil condition monitoring and remaining useful life prediction technique based on a particle filtering algorithm and commercially available online sensors. This technique is developed by integrating lubrication oil degradation physical models with the particle filtering algorithm. The physical models are used to simulate the deterioration process of the lubrication oil due 
to water contamination in terms of the kinematic viscosity and dielectric constant. A simulation case study based on lab verified models is used to demonstrate the effectiveness of the technique.

In this paper, a particle filtering algorithm is utilized as RUL prediction tool. For oil condition monitoring, an effective and accurate state estimation tool will be beneficial to reduce machine downtime. An on-line RUL estimator includes two stages: state estimation and RUL prediction. First, in the state estimation stage, even though there are many state estimation techniques, Kalman filter and particle filter are the most utilized ones. However, Kalman filter requires many assumptions such as: 1) zero-mean Gaussian process noise, 2) zero-mean Gaussian observation noise, 3) Gaussian posterior probability density function (pdf), etc. Because nonlinear Kalman filter is linearization based technique, if the system nonlinearity grows, any of linearization (either local or statistical linearization) methods breaks down (Merwe et al., 2000). Second, in RUL estimation stage, particle filtering can handle statistic prediction data unlike the other methods (parameter estimation). As a result, particle filtering algorithm provides feasible solutions for a wide range of RUL predication applications. A particle filtering algorithm integrated with physics based oil degradation models will provide a basis to develop practically feasible tools for accurate RUL prediction of lubrication oil.

The remainder of the paper is organized as follows. Section 2 is focused on the development of an online lubrication oil health monitoring and remaining useful life prediction tool using a kinematic viscometer and dielectric constant sensor. In this section, physical models that simulate the kinematic viscosity and dielectric constant as a function of the water contamination level and temperature are presented. The validation of the physical models using the experimental data is performed. The developed physical models are then integrated into a particle filtering framework to develop the lubrication oil remaining useful life prediction tool. The developed tool is then illustrated with a simulation case study based on lab verified models. Finally, Section 3 concludes the paper.

\section{DEVELOPMENT OF LUBRICATION OIL RUL PREDICTION TOOL}

\subsection{Lubrication Oil Deterioration Models Due To Water Contamination}

In this section, physical models that represent lubrication oil deterioration due to water contamination in terms of viscosity and dielectric constant are presented. Since experimental approach has certain disadvantages including limited degradation scenario coverage, long pre-installation training time and unavoidable test errors, the physical models can be built aiming at eliminating all those shortcomings and provide an accurate/ideal sensor output which reflects the actual health status of the lubricant oil. Water contamination is selected as a representative basic degradation feature. Using the physical models, given any temperature and a water contamination ratio, one could simulate the kinematic viscometer and the capacitance sensor outputs with maximum accuracy.

\subsubsection{Kinematic Viscosity}

Define:

$T=$ temperature, in Celsius

$V_{o i l, T}=$ viscosity of the healthy oil at temperature $T$, in Cst

$V_{\text {water }, T}=$ viscosity of the water at temperature $T$, in Cst

$P=$ water volume percentage

According to Stachowiak and Batchelor (2005), water and oil mixture viscosity at a certain temperature $V_{M, T}$ can be computed as:

$$
V_{M, T}=\left(V_{o i l, T}-V_{\text {water }, T}\right) \times(1-P)+V_{\text {water }, T}
$$

where:

$$
V_{\text {water }, T}=-0.451 \times \ln T+2.3591
$$

Note that in Eq. (1), $V_{\text {oil,T }}$ is defined as the healthy lubrication oil information and is extracted from our initial test while $V_{\text {water, }}$ is defined as the water physical attribute which can be considered known factors. Based on Equation (1), we can compute the degree of oil degradation as the result of water contamination in terms of viscosity as: $D D_{\text {viscosity }}=\frac{V_{M, T}}{V_{\text {oil }, T}}$.

Equation (1) represents the kinematic viscosity of the degraded oil as a function of temperature and water contamination ratio.

\subsubsection{Dielectric Constant}

Define:

$\varepsilon_{\text {oil }, T}=$ dielectric constant of healthy oil at temperature $T$

$\varepsilon_{\text {water }, T}=$ dielectric constant of water at temperature $T$

According to Jakoby and Vellekoop (2004), the dielectric constant of water and oil mixture at a certain temperature $\varepsilon_{M, T}$ can be computed as:

$\varepsilon_{M, T}=$

$\varepsilon_{\text {oil }, T} \times\left(1+3 \times P \times \frac{\varepsilon_{\text {water }, T}-\varepsilon_{\text {oil }, T}}{\varepsilon_{\text {water }, T}+2 \times \varepsilon_{\text {oil }, T}-P \times\left(\varepsilon_{\text {water }, T}-\varepsilon_{\text {oil }, T}\right)}\right)$

where:

$$
\varepsilon_{\text {water }, T}=80-0.4 \times((T+273)-293)
$$




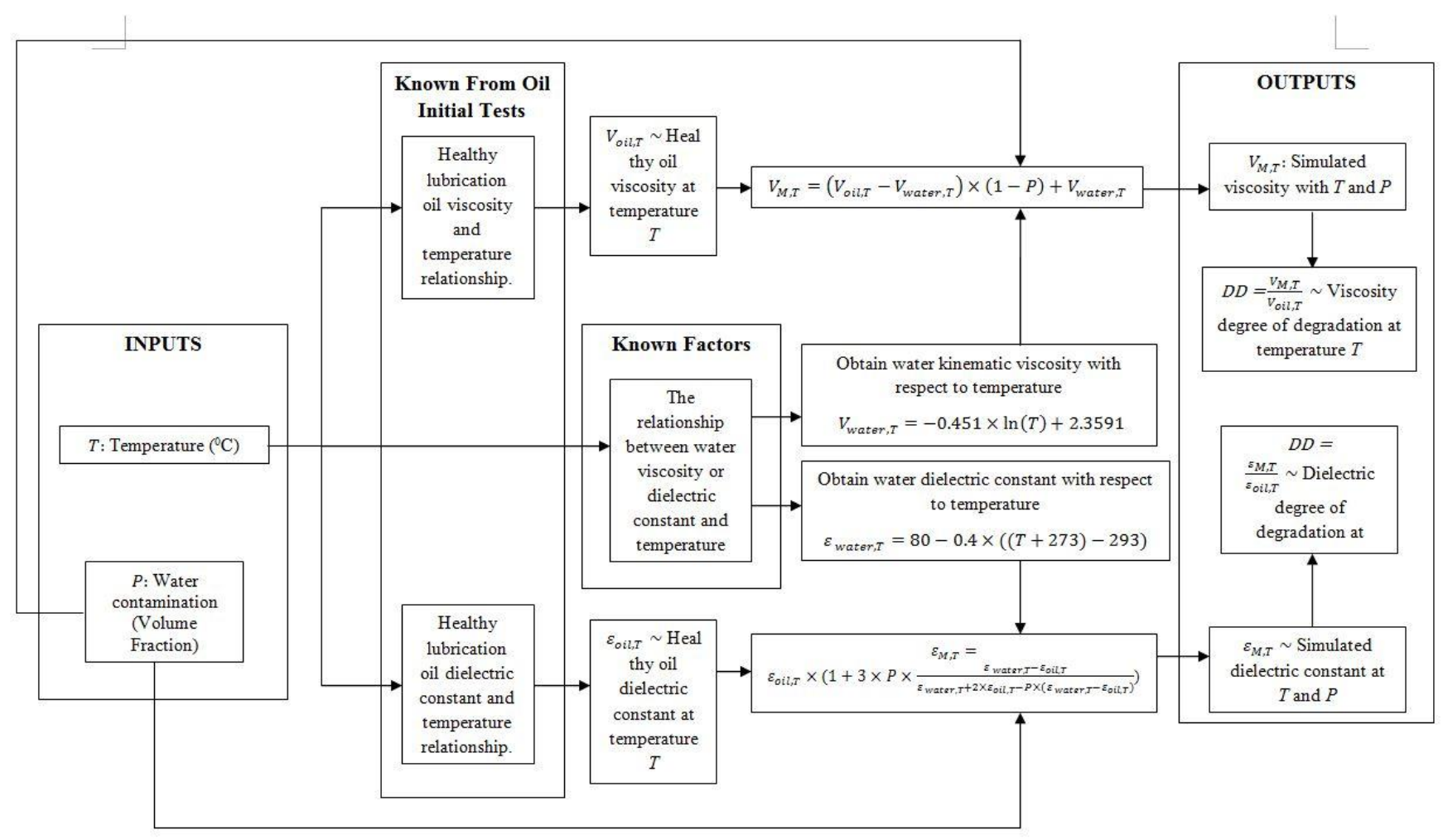

Figure 2. Lubrication oil water contamination simulation model for viscosity and dielectric constant

Note that in Eq. (3), $\varepsilon_{o i l, T}$ is defined as the healthy lubrication oil information and is extracted from our initial test while $\varepsilon_{\text {water,T }}$ is defined as the water physical attribute which can be considered known factors. Based on Equation (3), we can compute the degree of oil degradation as the result of water contamination in terms of dielectric constant as: $D D_{\text {dielectric constant }}=\frac{\varepsilon_{M, T}}{\varepsilon_{\text {oil }, T}}$.

Equation (3) represents the dielectric constant of the degraded oil as a function of temperature and water contamination ratio.

The simulation application of the lubrication oil deterioration model due to water contamination in terms of viscosity and dielectric constant can be summarized in Fig. 2. The simulation input is the temperature and water contamination ratio. The simulation output is the degraded oil kinematic viscosity and dielectric constant. Using the simulation application, one could generate a series of viscosity and dielectric constant values accordingly to reflect the true status of the lubrication oil.Experimental Validation of the Physical Models

\subsubsection{Experimental Setup}

In this section, the experiment setup using both capacitance and viscosity sensors are presented. In order to obtain the viscosity and the dielectric constant data, VISCOpro2000 from Cambridge Viscosity Inc. and Oil quality sensor from
GILL Sensor were used. For the kinematic viscometer, the sensor output data with a RS232 port and was connected to Window PC through a RS232 and USB converter. The software interface on the PC was HyperTerminal that comes with Microsoft Windows XP. The viscometer involves a piston that dipped into the test lubricant and the coils inside the sensor body magnetically force the piston back and forth a predetermined distance. By alternatively powering the coils with a constant force, the round trip travel time of piston is measured. An increase in viscosity is sensed as a slowed piston travel time. The time required for the piston to complete a two way cycle is an accurate measure of viscosity. The practical unit of viscosity is centipoises $(\mathrm{Cp})$, which is identical to the MKS unit $\mathrm{mPa} s$ (The viscosity of water is approximately $1 \mathrm{Cp}$ ). The viscosity sensor and its data acquisition system are shown in Fig.3. As we programmed according to the use manual that comes with the sensor. The sensor will send out analogue output including absolute viscosity, temperature compensated viscosity and the according temperature along with the date and time.

The dielectric constant sensor from Gill Sensor Inc. measures the capacitance of the test liquid then calculate the dielectric constant by the equation $\mathrm{D}=$ Coil/Cair, which is the capacitance of the test liquid divided by the capacitance of air, then output a voltage accordingly. The output analog signal was captured by LabJack U12 which was the data acquisition unit for the sensor and the voltage signal was 
recorded with Logger and Scope, software that comes with the U12.

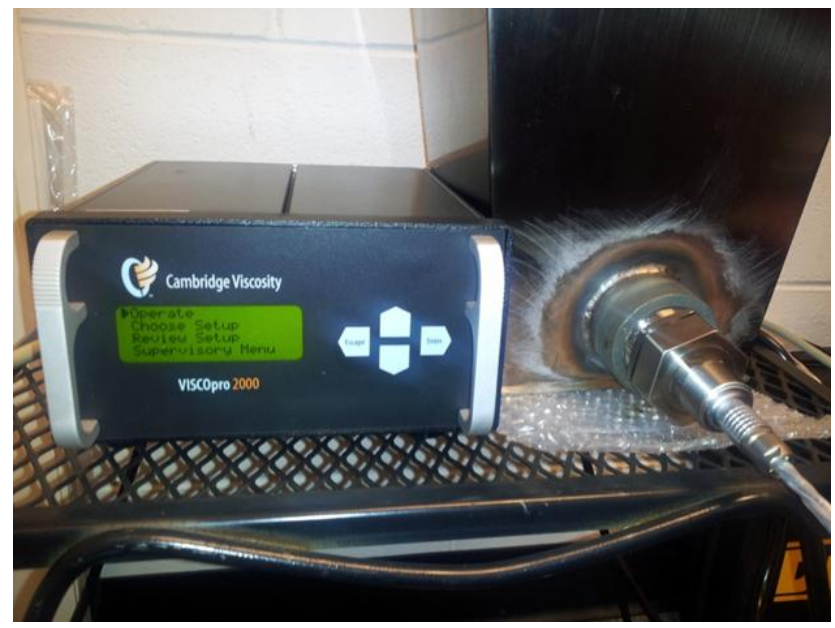

Figure 3. Viscometer and its data acquisition system

The dielectric constant sensor and its data acquisition system along with the entire experiment setup are shown in Fig. 4 and 5.

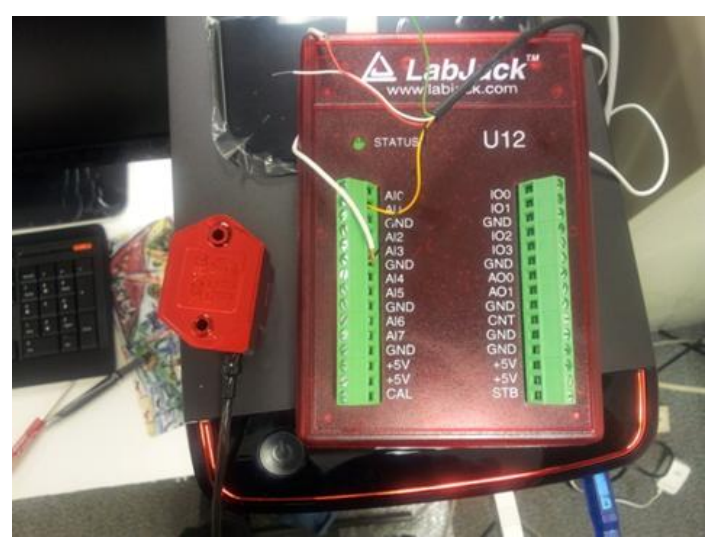

Figure 4. Dielectric constant sensor and the LabJack U12 data acquisition system

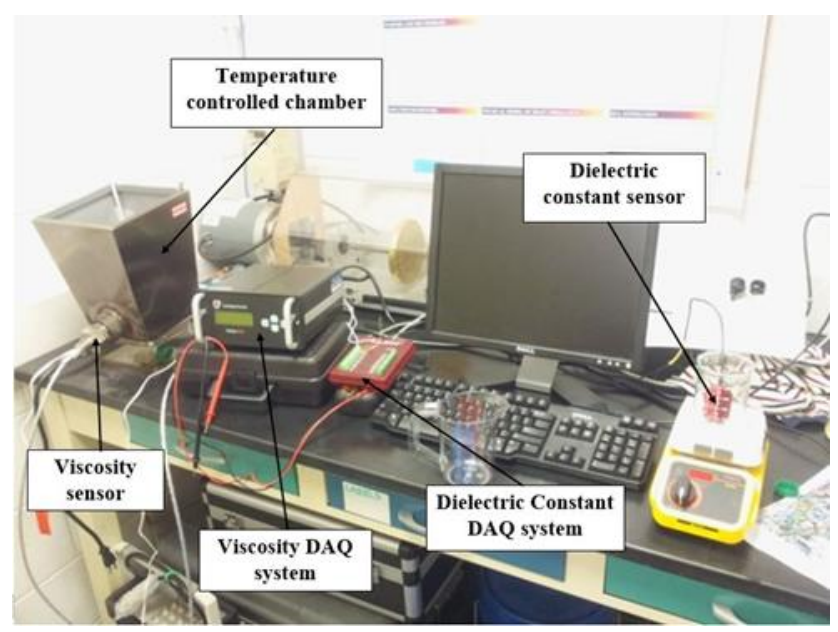

Figure 5. Experimental setup
Also needed for the tests are temperature control units. For the Dielectric constant test, we used a Hotplate from Thermo Scientific. It is a ceramic hotplate with temperature control and digital indication of temperature on the contact surface. However, since the viscometer had to be installed with sensor side facing up, we installed the sensor on a steel container and heated the oil inside with a liquid heater. In both situations, the test oils were preserved in a temperature controlled container and heated from around 25 to approximately 60 degrees Celsius. Instant temperatures were recorded along with the according viscosity and dielectric constant.

\subsubsection{The Validation Results}

In order to validate the physical models, viscometer and dielectric constant sensor readings under different water contamination levels with varying temperatures were compared with those computed from the physical models under the same conditions.

During the experiment, Castrol SAE 15W-20 lubrication oil was selected to perform the physical model validation. The healthy SAE 15W-20 lubrication oil kinematic viscosity in relation with temperature was obtained from the experimental tests as following:

$$
V_{\text {oil }, T}=57470.5189 \times T^{-1.935} \text {; }
$$

Also, the healthy SAE $15 \mathrm{~W}-20$ lubrication oil dielectric constant in relationship with temperature was obtained from the experimental tests as following:

$$
\varepsilon_{o i l, T}=4.90028 \times T^{-0.121} ;
$$

Fig. 6, 7, 8, and 9 show the plots of the kinematic viscosity obtained from the experiments and the physical models at water contamination level of $0.5 \%, 1 \%, 2 \%$, and $3 \%$, respectively. 40 data points were used to validate the viscosity physical model.

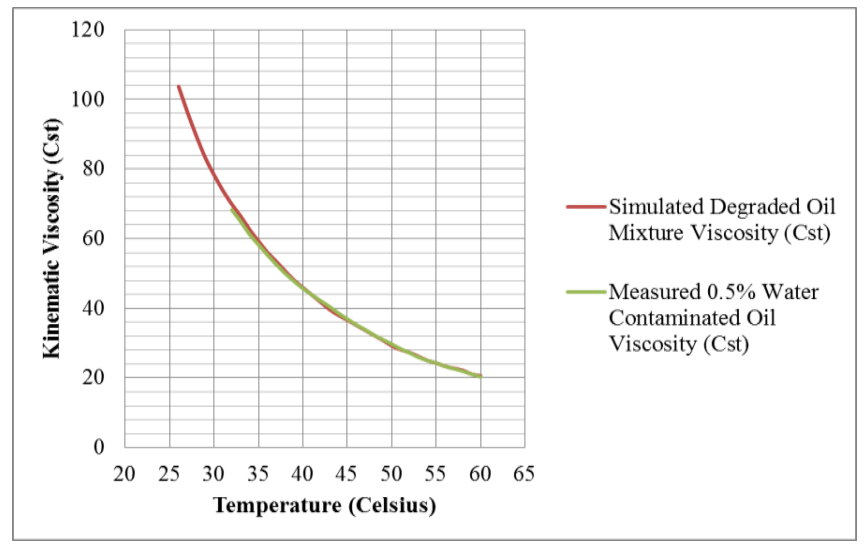

Figure 6. Kinematic viscosity comparison between simulated $0.5 \%$ water contaminated oil and measured $0.5 \%$ water contaminated oil 
Judging from the kinematic viscosity curves, the experiment result validated the simulation result. For a fixed water contamination level, as temperature increases the viscosity drops, the measured viscosity variation follows the pattern of the simulated kinematic viscosity curves.

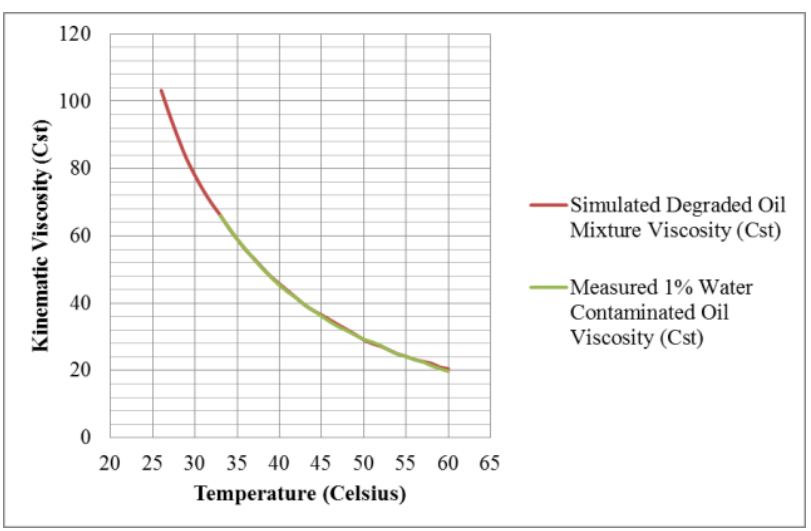

Figure 7. Kinematic viscosity comparison between simulated $1 \%$ water contaminated oil and measured $1 \%$ water contaminated oil

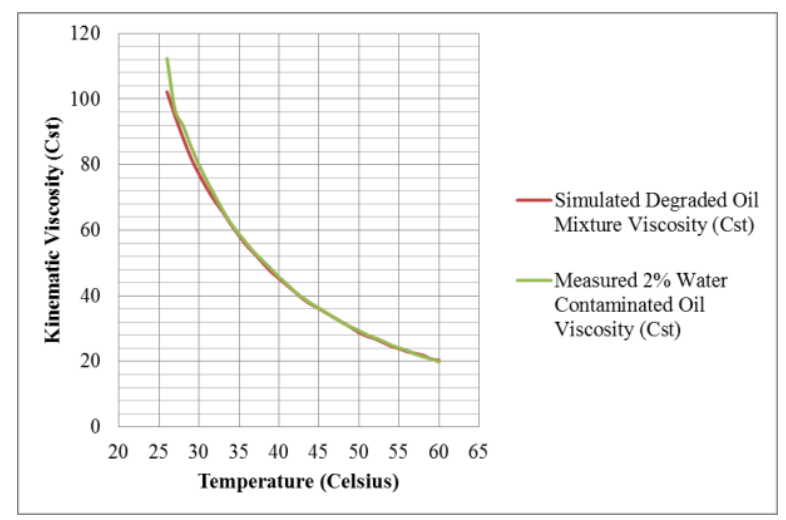

Figure 8. Kinematic viscosity comparison between simulated $2 \%$ water contaminated oil and measured $2 \%$ water contaminated oil.

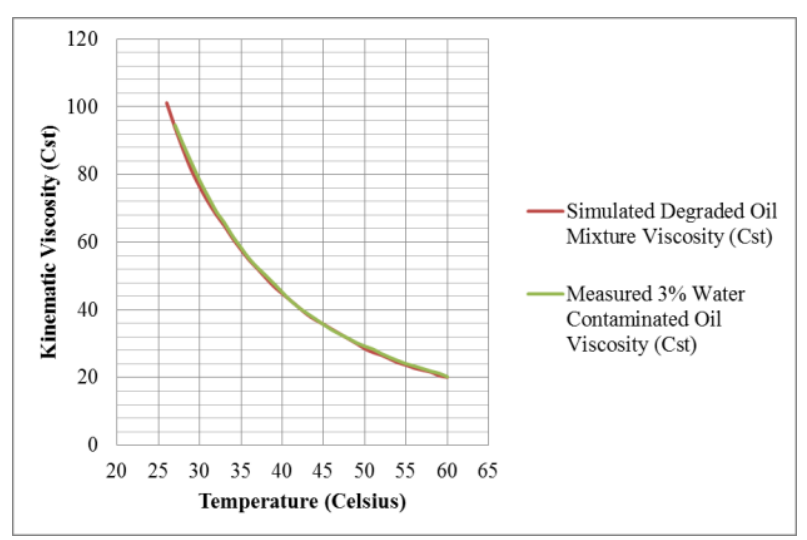

Figure 9. Kinematic viscosity comparison between simulated $3 \%$ water contaminated oil and measured $3 \%$ water contaminated oil
Fig.10 shows the plots of the dielectric constant obtained from the experiments and the physical models at water contamination level of $0.5 \%$. 40 data points were used to validate the dielectric constant physical model. Similar to the case of kinematic viscosity, the experiment result validated the simulation result. For a fixed water contamination level, as temperature increases the dielectric constant increases, the dielectric constant variation follows the pattern of the simulated dielectric constant curves. The dielectric constant physical model has been validated by Jakoby and Vellekoop (2004) for lubrication oil applications.

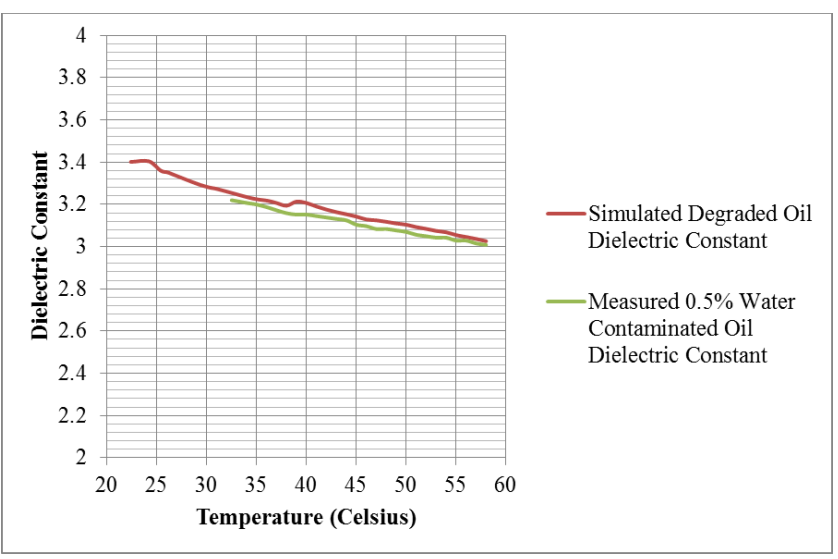

Figure 10. Dielectric constant comparison between simulated $0.5 \%$ water contaminated oil and measured $0.5 \%$ water contamination oil

\subsection{Lubrication Oil RUL Prediction Using Particle Filters}

Using particle filter for RUL prediction is a recent development in combining both physics based and data driven approaches for prognostics (He et al., 2012). Applications of particle filters to prognostics have been reported in the literature, for example, remaining useful life predication of a mechanical component subject to fatigue crack growth (Zio and Peloni, 2011), online failure prognosis of UH-60 planetary carrier plate subject to axial crack growth (Orchard and Vachtsevanos, 2011), degradation prediction of a thermal processing unit in semiconductor manufacturing (Butler and Ringwood, 2010), and prediction of lithium-ion battery capacity depletion (Saha et al., 2009). The reported application results have shown that particle filters represent a potentially powerful prognostics tool due to its capability in handling nonlinear dynamic systems and non-Gaussian noises using efficient sequential importance sampling to approximate the future state probability distributions. Particle filters were developed as an effective online state estimation tool (see Doucet et al., 2000; Arulampalam et al., 2002). In this paper, an integrated approach using particle filters for lubrication oil RUL prediction is presented. 


\subsubsection{Particle Filter for State Estimation}

Applying particle filters to state estimation will be discussed first. Particle filters are used to estimate the state of a dynamic system using state and observation parameters. The state transition function represents the degradation in time of the lubrication oil. The observation or measurement represents the relationship between the degradation state of the lubrication oil and the health monitoring sensor outputs.

To apply particle filtering method, state estimation problem should be formulated first as stated by Yoon (2012). The problem of state estimation (a.k.a. filtering) is to estimate the dynamic state in terms of the posterior probability density function (pdf), based on all available information, including the sequence of measurements up to the current time step $k$. Let us introduce $x_{k} \in \mathbb{R}^{n x}$ and $z_{k} \in \mathbb{R}^{n z}$ which represent system state vector and observation (or measurement) vector at the current time $\mathrm{k}$ respectively, where $n x$ and $n z$ are the dimension of the corresponding state vector and observation vector; $\mathbb{R}$ is a set of real numbers; $k \in \mathbb{N}$ is the time index; and $\mathbb{N}$ is the set of natural numbers. Consider the following discrete-time hidden Markov model (a.k.a state transition and observation model):

$$
\begin{gathered}
\boldsymbol{X}_{\boldsymbol{k}} \mid\left(\boldsymbol{X}_{\boldsymbol{k}-\mathbf{1}}=x_{k-1}\right) \triangleq p\left(x_{k} \mid x_{k-1}\right) \\
\boldsymbol{Z}_{\boldsymbol{k}} \mid\left(\boldsymbol{X}_{\boldsymbol{k}}=x_{k}\right) \triangleq p\left(z_{k} \mid x_{k}\right)
\end{gathered}
$$

where $\boldsymbol{X}_{\boldsymbol{k}}=\left\{x_{0}, x_{1}, \ldots, x_{k}\right\}$ is the sequence of the system state up to time $\mathrm{k} \in \mathbb{N}$, and $\boldsymbol{Z}_{\boldsymbol{k}}=\left\{z_{0}, z_{1}, \ldots, z_{k}\right\}$ is the sequence of observation that is available up to current time k. Note that the above notation $\boldsymbol{X}_{\boldsymbol{k}}$ is sometimes represented as $\mathrm{x}_{0: \mathrm{k}}$. Also, the state transition and the state observation models can be rewritten in functional form as follows:

$$
\begin{gathered}
x_{k}=f_{k-1}\left(x_{k-1}, v_{k-1}\right) \\
z_{k}=h_{k}\left(x_{k}, w_{k}\right)
\end{gathered}
$$

where $v_{k} \in \mathbb{R}^{\mathrm{nv}}$ and $w_{k} \in \mathbb{R}^{\mathrm{nw}}$ denote the process noise and measurement noise at time $\mathrm{k}$ respectively; $v_{k}$ and $w_{k}$ are white noise; the initial state distribution $p\left(x_{0}\right) \triangleq$ $p\left(x_{0} \mid z_{0}\right)$ is assumed known. Note that the state transition function is a mathematical representation of the lubrication oil degradation in time. Also, the observation model represents the health monitoring sensor outputs indicating the degradation state of the lubrication oil.

Then, the marginal pdf of the state can be recursively obtained in two steps: prediction and update. In the prediction step, suppose the state estimate at the time $\mathrm{k}-1$ $p\left(x_{k-1} \mid Z_{k-1}\right)$ is known. Then the prediction (or prior) pdf of the state is obtained involving the system model via the Chapman-Kolmogorov equation as:

$p\left(x_{k} \mid \boldsymbol{Z}_{\boldsymbol{k}-\mathbf{1}}\right)=\int p\left(x_{k} \mid x_{k-1}\right) p\left(x_{k-1} \mid \boldsymbol{Z}_{\boldsymbol{k}-\mathbf{1}}\right) d x_{k-1}$
In the update step, the new measurement $z_{k}$ becomes available and the posterior pdf can be obtained via the Bayes rule as follows:

$$
p\left(x_{k} \mid Z_{k}\right)=\frac{p\left(z_{k} \mid x_{k}\right) p\left(x_{k} \mid Z_{k-1}\right)}{p\left(z_{k} \mid Z_{k-1}\right)}
$$

where the normalizing constant is:

$$
\mathrm{p}\left(\mathrm{z}_{\mathbf{k}} \mid \mathbf{Z}_{\mathbf{k}-\mathbf{1}}\right)=\int p\left(x_{k} \mid \mathbf{Z}_{\boldsymbol{k}-\mathbf{1}}\right) p\left(z_{k} \mid x_{k}\right) d x_{k}
$$

The above obtained recursive propagation of the posterior pdf is a conceptual solution; it cannot analytically determined.

In any state estimation problem, based on the desired accuracy and processing time, a wide variety of tracking algorithms can be utilized. Especially, particle filter (a kind of suboptimal filter) increases accuracy while minimizing assumptions on the dynamic and measurement models. Due to its general disposition, particle filter became widely used in various filed. In the particle filter process, the marginal posterior density at time $k$ can be approximated as follows:

$$
p\left(x_{k} \mid Z_{k}\right) \approx \sum_{i=1}^{N} w_{k}^{i} \delta\left(x_{k}-x_{k}^{i}\right)
$$

where $\left\{\mathrm{x}_{\mathrm{k}}^{i}, w_{k}^{i}\right\}_{i=1}^{N}$ represents the random measure of the posterior pdf $p\left(x_{k} \mid Z_{k}\right) ;\left\{x_{k}^{i}, i=1, \ldots, N\right\}$ is a set of support points with associated weights $\left\{w_{k}^{i}, i=1, \ldots, N\right\} ; \delta(\cdot)$ is a Dirac delta function; and sum of weights $\sum_{i} w_{k}^{i}=1$. Since we are not able to directly sample from the posterior $p\left(x_{k} \mid \boldsymbol{Z}_{\boldsymbol{k}}\right)$ itself, associated weights $w_{k}^{i}$ are computed by introducing importance density $q\left(x_{k} \mid \boldsymbol{Z}_{\boldsymbol{k}}\right)$ which is chosen easily sample from (normally transitional prior is used):

$$
w_{k}^{i} \propto \frac{p\left(x_{k}^{i} \mid \boldsymbol{Z}_{k}\right)}{q\left(x_{k}^{i} \mid \boldsymbol{Z}_{\boldsymbol{k}}\right)}
$$

Thus, the desired posterior and weight update can be factorized in recursive forms as:

$$
\begin{gathered}
p\left(x_{k} \mid \boldsymbol{Z}_{\boldsymbol{k}}\right) \propto p\left(z_{k} \mid x_{k}\right) p\left(x_{k} \mid x_{k-1}\right) p\left(x_{k-1} \mid \boldsymbol{Z}_{\boldsymbol{k}-\mathbf{1}}\right) \\
\mathrm{w}_{\mathrm{k}}^{i}=w_{k-1}^{i} \frac{p\left(z_{k} \mid x_{k}^{i}\right) p\left(x_{k}^{i} \mid x_{k-1}^{i}\right)}{q\left(x_{k}^{i} \mid x_{k-1}^{i}, z_{k}\right)}
\end{gathered}
$$

Note that, after the weights are obtained via (11), weight normalization is required $\left(\sum_{i} w_{k}^{i} \neq 1\right)$ to satisfy the nature of probability density function $\left(\sum_{i} w_{k}^{i}=1\right)$ as follows:

$$
\mathrm{w}_{\mathrm{k}}^{i}=\frac{w_{k}^{i}}{\sum_{j} w_{k}^{j}}
$$

It can be shown that $\lim _{\mathrm{N} \rightarrow \infty}\left\{\mathrm{x}_{\mathrm{k}}^{\mathrm{i}}, w_{k}^{i}\right\}_{i=1}^{\mathrm{N}}=p\left(x_{k} \mid Z_{k}\right)$. 


\subsubsection{Particle Filter for RUL Prediction}

In order to apply particle filter to estimate the remaining useful life (RUL), an $l$-step ahead estimator is required. An $l$-step ahead estimator will provide a long term prediction of the state pdf $p\left(x_{k+l} \mid \boldsymbol{Z}_{\boldsymbol{k}}\right)$, for $l=1, \ldots, T-k$, where $T$ is the time horizon of interest (i.e. time of failure). In making an $l$-step ahead prediction, it is necessary to assume that no information is available for estimating the likelihood of the state following the future $l$-step path $\boldsymbol{X}_{k+1: k+l}$, that is, future measurements $z_{k+l}$, for $l=1, \ldots, T-k$ cannot be used for updating the prediction. In other word, the desired state pdf of particular future time $p\left(x_{k+l} \mid \boldsymbol{Z}_{\boldsymbol{k}}\right)$ can be factorized with the current posterior pdf $p\left(x_{k} \mid \boldsymbol{Z}_{\boldsymbol{k}}\right)$ to desired $p\left(x_{k+l} \mid \boldsymbol{Z}_{\boldsymbol{k}}\right)$ and the state transition function $p\left(x_{k} \mid x_{k-1}\right)$ as $\prod_{j=k+1}^{k+l} p\left(x_{j} \mid x_{j-1}\right)$. By combining Eq. (7) and (10), an unbiased $l$-step ahead estimator can be obtained as stated by Zio and Peloni (2011), as well as Orchard and Vachtsevanos (2009).

$$
=\int \ldots \int \prod_{j=k+1}^{k+l} p\left(x_{j} \mid x_{j-1}\right) p\left(x_{k} \mid \boldsymbol{Z}_{\boldsymbol{k}}\right) \prod_{j=k}^{k+l-1} d x_{j}
$$

Despite the fact that an unbiased estimator provides the minimum variance estimation, solving equation (13) can be either difficult or computationally expensive. Thus, a sampling based approximation procedure of the $l$-step-ahead estimator is provided by Zio and Peloni (2011).

Assume that the state $x_{t=k}$ represents the particle contamination level at the current time $k$, the particle contamination level increases by time and RUL is the object's remaining usable time before it fails (or needs maintenances). If an $l$-step-ahead state from the time $k$ (i.e. $x_{t=k+l}$ ) goes across a pre-specified critical value $\lambda$ (i.e. $x_{t=k+l} \geq \lambda$ ), the object's RUL at the time $k$ can be computed as $\mathrm{RUL}_{\mathrm{k}}=(k+l)-k=l$. At each time step before its failure (i.e. $t \leq k+l$ ), the state $x_{t \leq k+l}$ would be projected up to the future time of failure $t=k+l$. In this manner, estimating RUL $\leq l$ is equivalent to estimating $x_{k+l} \geq \lambda$, rewriting as:

$$
\hat{p}\left(R U L \leq l \mid \boldsymbol{Z}_{\boldsymbol{k}}\right)=\hat{p}\left(\boldsymbol{X}_{\boldsymbol{k}+\boldsymbol{l}} \geq \lambda \mid \boldsymbol{Z}_{\boldsymbol{k}}\right)
$$

When RUL ( $l$-step-ahead prediction) is implemented using particle filter as stated by He, et al. (2012) corresponding weights are computed by introducing an estimated measurement $\widehat{z_{k+n}}$ according to Eq. (10) (i.e. measurement model) as:

$$
\widehat{\mathbf{z}_{k+n}} \sim h_{k+n}\left(\widehat{\mathrm{x}_{k+n}}\right)
$$

where $n$ is a future time step $0<n \leq l$. Then, the updating process is accomplished by Eq. (12) and (13). While RUL is computed, no measurement errors for the estimated measurements $\widehat{Z_{k+n}}$ are considered. Note that the actual system has not been altered. Zero measurement errors are only applied in order to predict $l$-step-ahead state $\hat{p}\left(\boldsymbol{X}_{\boldsymbol{k}+\boldsymbol{l}} \geq\right.$ $\left.\lambda \mid \boldsymbol{Z}_{\boldsymbol{k}}\right)$ because the future observation values are never accessible. In this paper, an integrated prognostic technique using the $l$-step-ahead RUL estimating particle filter is exploited.

\subsection{Simulation Case Study}

In order to validate and demonstrate the effectiveness of the particle filter technique based lubrication oil RUL prediction approach, a simulation case study was conducted. In this simulation case study, a scenario of lubrication oil deterioration due to water contamination was simulated with the physical models presented in Sections 2.1.1 and 2.1.2. In this scenario, a temperature template was used to simulate a daily temperature variation of the wind turbine as shown in Figure 11.

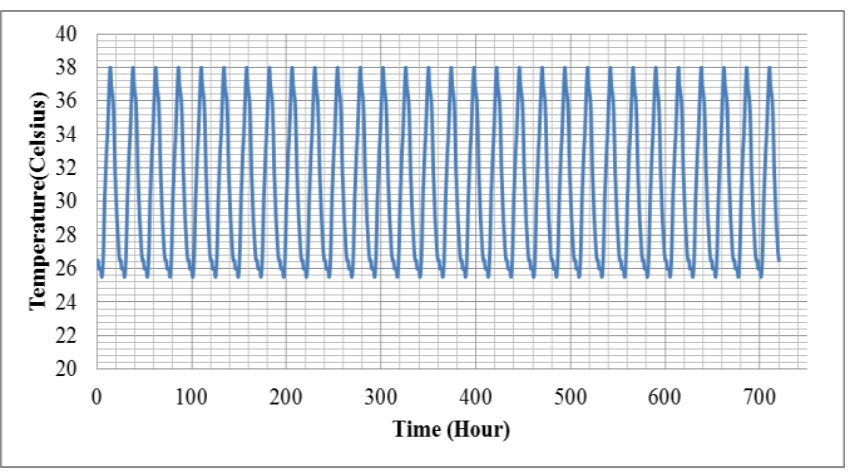

Figure 11. Temperature variation template

The other aspects of the simulation were defined as follows:

1. The deterioration state of the lubrication oil was defined as the water contamination level $P$.

2. The viscometer and dielectric constant sensor outputs were defined as observation data.

3. The lubrication oil deterioration process was simulated for 30 days (720 hours).

4. At the end of the simulation, the water contamination level $P$ reached at $5 \%$.

5. The sampling time interval was set to be every hour.

6. The failure threshold was set as $3 \%$ which was defined as the industry water contamination level limit.

7. At approximately the $525^{\text {th }}$ hour, the water contamination level reached $3 \%$.

Fig. 12 shows the water contamination propagation over 720 hours during the simulation with the given temperature. 


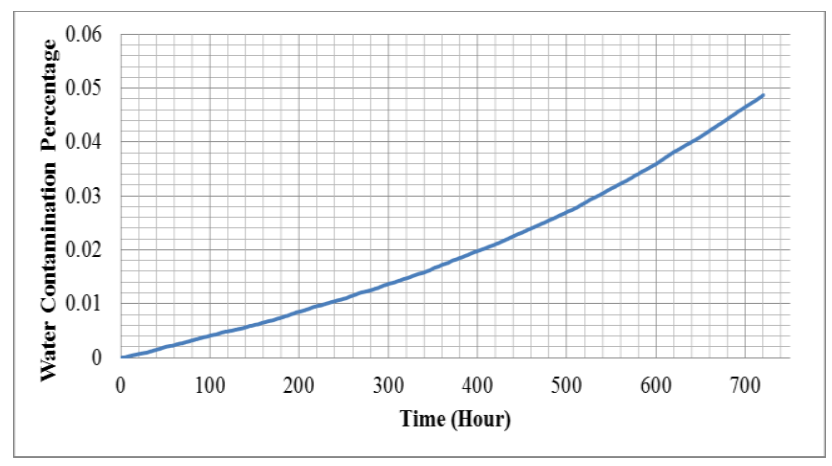

Figure 12. Water contamination propagation template

\subsubsection{Particle Filter Implementation for RUL Prediction}

To implement a particle filter for the RUL prediction of the lubrication oil in the simulation case study, the state transition function was defined as Eq. (22). It is generated as progression of the state of interest which in our case is the water contamination.

$$
X_{k+1}=1.0017 \times X_{k}+\operatorname{Random}(0,1) \times 0.00007
$$

Two observation functions could be established using kinematic viscosity and dielectric constant physical models as Eq. (23) and (24).

Note that Eq. (23) is the observation function expressed in terms of kinematic viscosity and Eq. (24) the observation function expressed in terms of dielectric constant.

Generalized observation function could be established by combining kinematic viscosity and dielectric constant as Eq. (25).

$$
\begin{gathered}
Z_{k}=\left(5740.5189 \times T_{k}^{-1.935}+0.451 \times \ln T_{k}-2.3591\right) \times\left(1-X_{k}\right)-0.451 \times \ln T_{k}+2.3591 \\
Z_{k}=4.90028 \times T_{k}^{-0.121} \times\left(1+3 \times X_{k} \times \frac{-0.4 \times T_{k}+88-4.90028 \times T_{k}^{-0.121}}{-0.4 \times T_{k}+88+9.80056 \times T_{k}^{-0.121}-X_{k} \times\left(-0.4 \times T_{k}-4.90028 \times T_{k}^{-0.121}\right)}\right) \\
Z_{k}=\left(\begin{array}{c}
\text { Viscosity } \\
D C_{k}
\end{array}\right]=\left[\begin{array}{l}
h_{1}\left(X_{k}, T_{k}\right) \\
h_{2}\left(X_{k}, T_{k}\right)
\end{array}\right]=\left[\begin{array}{l}
h_{1}\left(X_{k}, T_{k}\right) \\
h_{2}\left(X_{k}, T_{k}\right)
\end{array}\right]= \\
{\left[\begin{array}{c}
\left(57470.5189 \times T_{k}^{-1.935}+0.451 \times \ln \mathrm{T}_{\mathrm{k}}-2.3591\right) \times\left(1-X_{k}\right)-0.451 \times \ln \mathrm{T}_{\mathrm{k}}+2.3591 \\
4.90028 \times T_{k}^{-0.121} \times\left(1+3 \times X_{k} \times \frac{-0.4 \times T_{k}+88-4.90028 \times T_{k}^{-0.121}}{-0.4 \times T_{k}+88+9.80056 \times T_{k}^{-0.121}-X_{k} \times\left(-0.4 \times T_{k}-4.90028 \times T^{-0.121}\right)}\right)
\end{array}\right]}
\end{gathered}
$$

In the implementation of the particle filter, number of particles was fixed as 50 and the prediction started at time point $425^{\text {th }}$ hour during the simulation with $l$ being 100 time steps. The reason for selecting 50 particle populations is to balance accuracy and processing time. The particle population impact will be discussed in the Section 2.4.2.

In order to reduce observation data fluctuation and RUL prediction variation, a temperature compensation module was integrated into the physical models. With a reference to 30 degree Celsius, which was the median temperature of the operating condition over a 24 hours cycle, the observation data was adjusted according to viscosity or dielectric constant functions with respect to the temperature. For example, at a certain temperature, the temperature compensated viscosity was the true value of the viscosity plus the theoretical viscosity difference between $30^{\circ} \mathrm{C}$ and current temperature. The compensated value can be obtained from the following equations:

$$
\begin{aligned}
& \varepsilon_{\text {compensate }, T}=\varepsilon_{T}+\left(\varepsilon_{30}{ }^{\prime}+\varepsilon_{T}{ }^{\prime}\right) \\
& =\varepsilon_{T}+\left(\varepsilon_{30}{ }^{\prime}-\left(0.0001529 \times T^{2}-0.02241 \times T+3.901\right)\right) ; \\
& \varepsilon_{T}{ }^{\prime}=0.0001529 \times T^{2}-0.02241 \times T+3.901 ;
\end{aligned}
$$

$V_{\text {compensate } T}=V_{T}+\left(V_{30}{ }^{\prime}+V_{T}{ }^{\prime}\right)$

$=V_{T}+\left(V_{30}{ }^{\prime}-\left(0.21565 \times T^{2}-18.225 \times T+431.5\right)\right)$;

$V_{T}{ }^{\prime}=0.21565 \times T^{2}-18.225 \times T+431.5 ;$

Fig. 13 and Fig. 14 present the observation variation before the temperature compensation.

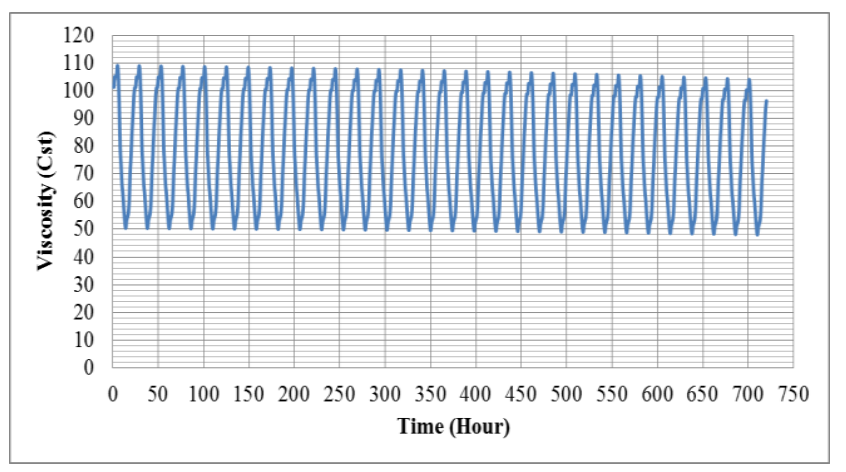

Figure 13. Observation data (kinematic viscosity) fluctuation before temperature compensation 


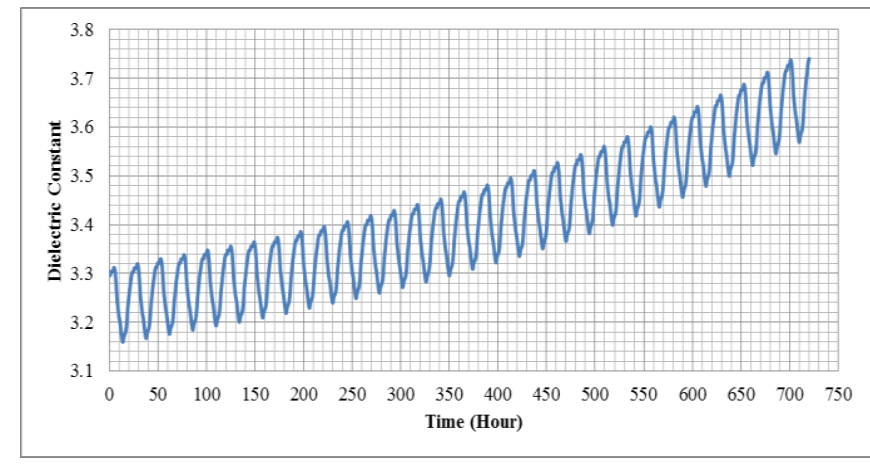

Figure 14. Observation data (dielectric constant) fluctuation before temperature compensation

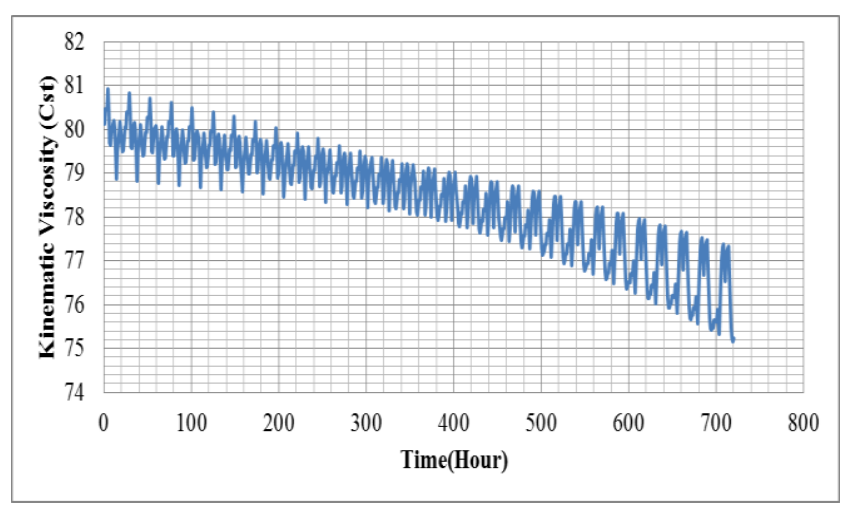

Figure 15. Observation data (kinematic viscosity) fluctuation after temperature compensation

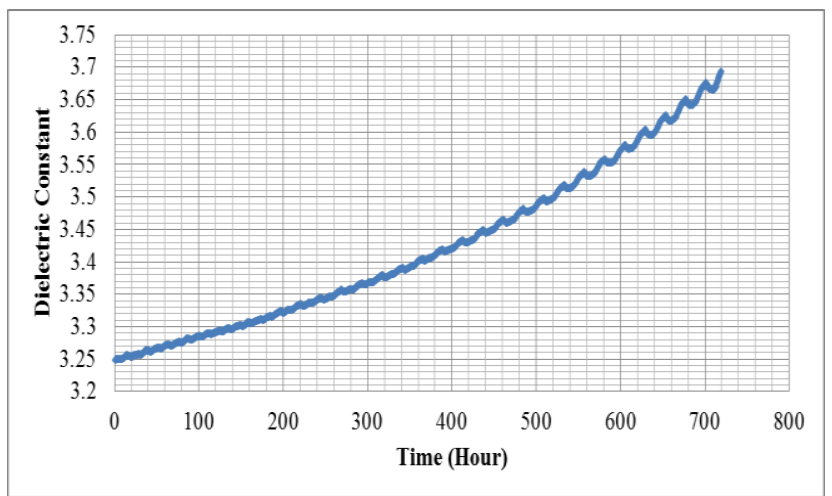

Figure 16. Observation data (dielectric constant) fluctuation after temperature compensation

Fig. 15 and Fig. 16 present the observation data variation after the temperature compensation.

In comparison of Fig. 13 with Fig.15, and Fig. 14 with Fig.16, it is obvious that the observation data fluctuation is greatly reduced after the temperature compensation and the data are ready for RUL prediction. Figure 17 summarizes the implementation of particle filter technique for lubrication oil RUL prediction.

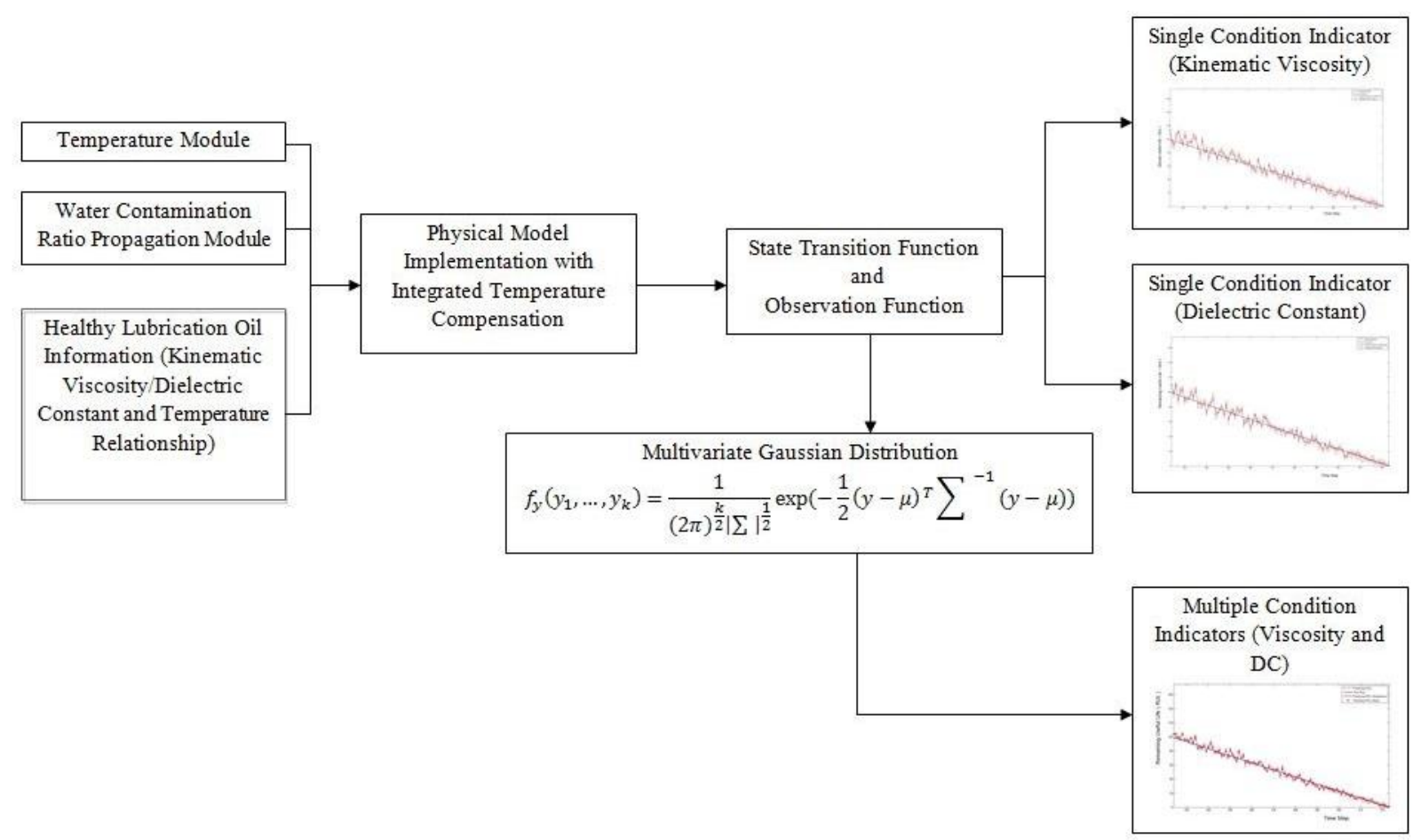

Figure 17. Particle filtering technique implementation. 


\subsubsection{RUL Prediction Results Using one Sensor Observation}

Using the particle filter technique, RUL of the lubrication oil was predicted with either the viscosity or dielectric constant sensor observation. The prediction results are provided in Fig. 18 and Fig. 19, respectively. The $x$ axis represents the true simulation time step. The $y$ axis represents the time steps until failure. The blue line is the true remaining useful life and the red dots are our prediction mean while the vertical red bars are the $90 \%$ confidence intervals. From Fig. 18 and Fig. 19, one can see that with a certain degree of fluctuation at the beginning, the prediction becomes more and more accurate towards the end for both predictions. For a comparison purpose, the RUL prediction results with 200 particles are provided in Fig. 20. As one can observe, using the same dielectric constant sensor observation under the same condition, a larger particle population provide better accuracy. However, larger particle population requires more processing times. The relationship between particle population and processing times is shown in Table 2.

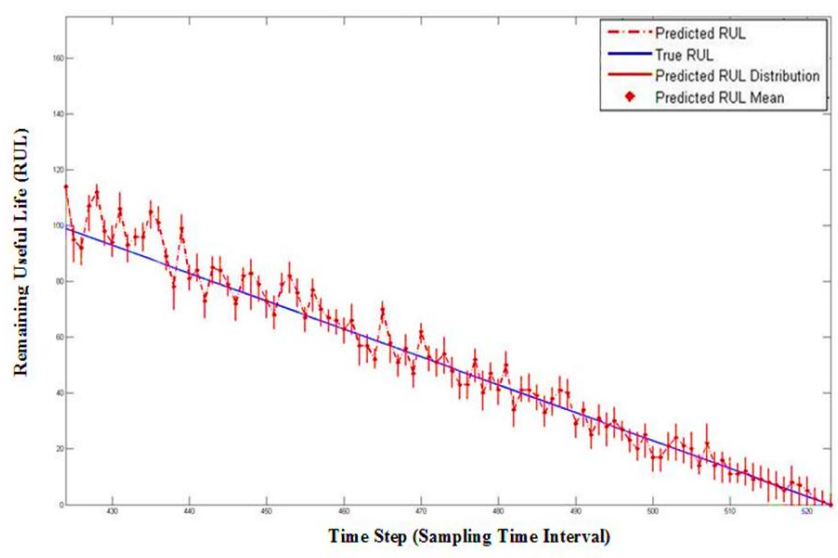

Figure 18. RUL prediction with only kinematic viscosity observation data (particle population $=50$ )

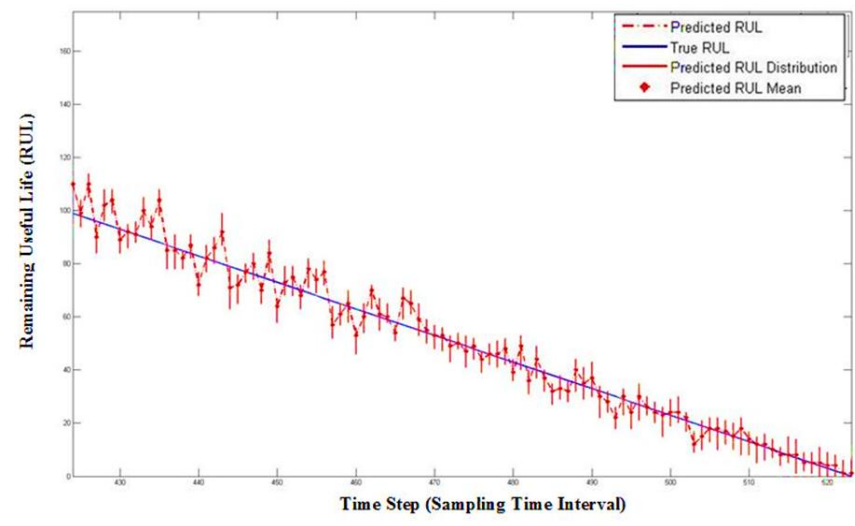

Figure 19. RUL prediction with only dielectric constant observation data (particle population $=50$ )

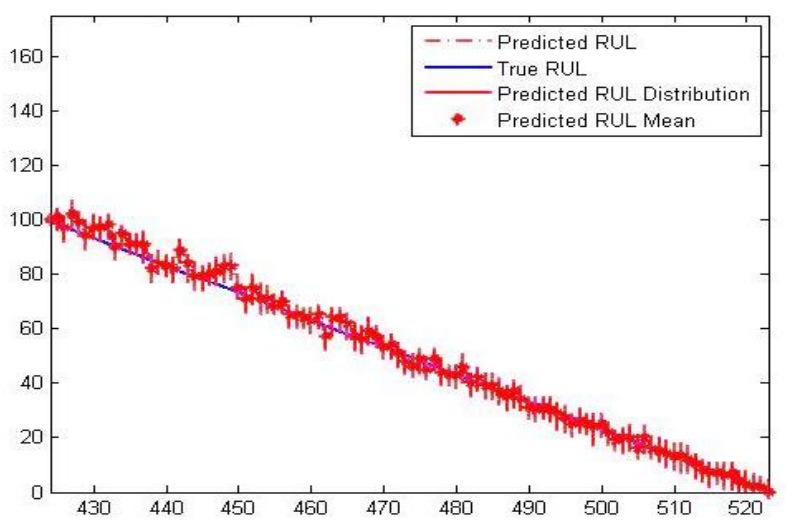

Figure 20. RUL prediction with only dielectric constant observation data (particle population $=200$ )

\begin{tabular}{|c|c|}
\hline Particle Population (N) & Prediction Time \\
\hline 50 & 3 minutes 49 seconds \\
\hline 75 & 4 minutes 40 seconds \\
\hline 100 & 5 minutes 47 seconds \\
\hline 150 & 7 minutes 59 seconds \\
\hline 200 & 10 minutes 16 seconds \\
\hline
\end{tabular}

Table 2. Particle population and prediction time relationship with only dielectric constant observation data

\subsubsection{RUL Prediction Results Using Multiple Sensor Observation}

The RUL prediction results presented in previous section were obtained using only one sensor. In order to combine the two sensors into a particle filter based RUL prediction, a multivariable Gaussian distribution is used:

$f_{y}\left(y_{1}, \ldots, y_{k}\right)=\frac{1}{(2 \pi)^{\frac{k}{2}|\Sigma|^{\frac{1}{2}}}} \exp \left(-\frac{1}{2}(y-\mu)^{T} \Sigma^{-1}(y-\mu)\right)$

where $\Sigma$ is the covariance matrix of observations, $|\Sigma|$ is the determinant of $\Sigma$. Note that $y_{k}$ in Equation (30) represents the sensor output data $Z_{k}$.

By applying the probability density function, each particle will be assigned a weight according to its observation and updated similarly. The RUL prediction results of combining two sensors are provided in Fig. 21. As one can see from Figure 18, Figure 19, and Figure 21, in comparison with the RUL prediction results using only one sensor, the RUL prediction variation in combining two sensors has been reduced from the beginning until the end. Moreover, the accuracy of the prediction has also been improved significantly. The shortcoming of utilizing particle filtering 
algorithm is that it is considered a computational expensive algorithm. However, using particle filtering algorithm in combination with viscosity and dielectric constant based physical models would provide a feasible and effective solution for RUL predication of lubrication oil.

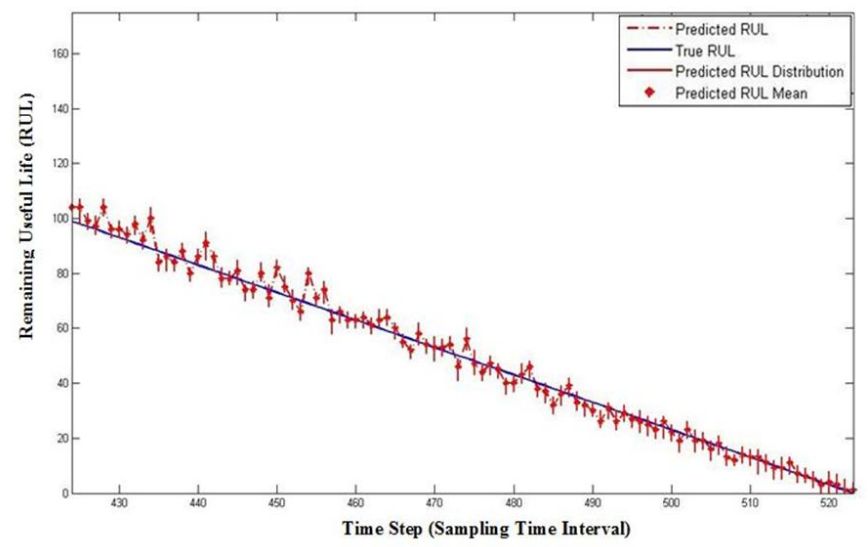

Figure 21. RUL prediction with both kinematic viscosity and dielectric constant observation data (particle population $=50$ )

\section{CONCLUSIONS}

Lubrication oil condition monitoring and RUL prediction is important for reliability and availability improvement of the wind turbines and reduction of maintenance costs for the wind industry. However, up to today, no effective physics based tools for online condition monitoring of lubrication oil and RUL prediction using viscosity and dielectric constant sensors have been reported. In this paper, a solution for online lubrication oil condition monitoring and RUL prediction using viscosity and dielectric constant sensors along with the particle filtering technique is presented. In particular, physics models for lubrication oil degradation with both viscosity and dielectric constant as performance parameters have been developed and validated with lab oil test data. These lab validated oil deterioration models were integrated with a particle filtering algorithm to develop an effective RUL prediction tool for water contaminated lubrication oil. The effectiveness of developed RUL prediction tool was validated with a simulation case study based on lab verified models.

The RUL prediction results of the simulation case study showed that when only one sensor was utilized, the RUL prediction with particle filtering had a slight fluctuation around the true RUL at the beginning of the prediction process. When both viscosity and dielectric sensors were used, the prediction fluctuation at the beginning was reduced and the RUL prediction accuracy was greatly improved throughout the entire prediction process. Also, larger particle population increase prediction accuracy. However, as particle population increases, the computational time for RUL prediction increases along with it.

\section{REFERENCES}

Agoston, A., Otsch, C., and Jakoby, B., 2005, "Viscosity sensors for engine oil condition monitoring-Application and interpretation of results.", Sensors and Actuators A, Vol. 121, pp. 327 - 332.

Agoston, A., Dorr, N., and Jakoby, B., 2006, "Online Application of sensors monitoring lubricating oil properties in biogas engines.", IEEE Sensors 2006, EXCO, Daegu, Korea, October 22 - 25, 2006

Agoston, A., Otsch, C., Zhuravleva, J., and Jakoby, B., 2004, "An IR-absorption sensor system for the determination of engine oil deterioration.", Proceeding of IEEE, sensors, Vienna, Austria, Otc. 24 - 27, 2004, Vol. 1, pp. $463-466$.

Agoston, A., Schneidhofer, C., Dorr, N., and Jakoby, B., 2008, "A concept of an infrared sensor system for oil condition monitoring", Elekrotechnik \& Informationstechnik., Vol. 125/3, pp. 71 - 75.

Arulampalam, S.M., Maskell, S., Gordon, N., and Clapp, T., 2002, "A Tutorial on Particle Filters for Online Nonlinear/Non-Gaussian Bayesian Tracking", IEEE Transactions on Signal Processing, Vol. 50, No. 2, pp. $174-188$.

Benner, J.J., Sadeghi, F., Hoeprich, M.R., and Frank. M.C., 2006, "Lubricating properties of water oil emulsions." Journal of Tribology, Transaction of ASME, April 2006. Vol. 128, pp. 296 - 311.

Beran, E., Los M. and Kmiecik, A., 2008, "Influence of thermo-oxidative degradation on the biodegradability of lubricant base oils", Journal of Synthetic Lubrication, Vol. 28, pp. 75 - 83.

BHRA, 1988, Condition Monitoring Supplement, Cranfield, Bedfordshire: BHRA.

Bozchalooi, I.S. and Liang, M., 2009, "Oil Debris Signal Analysis Based on Empirical Mode Decomposition for Machinery Condition Monitoring", 2009 American Control Conference, June 10 - 12, 2009, St. Louis, MO, USA

Butler, S. and Ringwood, J., 2010, "Particle Filters for Remaining Useful Life Estimation of Abatement Equipment used in Semiconductor Manufacturing", Proceedings of the First Conference on Control and Fault-Tolerant Systems, Nice, France, pp. 436 - 441.

Byington C., Palmer C., Argenna G., and Mackos N., 2010, "An integrated, real-time oil quality monitor and debris measurement capability for drive train and engine systems" Proceedings of American Helicopter Society 66th Annual Forum and Technology Display, Pheonix, Arizona, May 11 - 13, 2010

Byington, C., Mackos, N., Argenna, G., Palladino, A., Reimann, J., and Schmitigal, J., 2012, "Application of symbolic regression to electrochemical impedance 
spectroscopy data for lubricating oil health evaluation", Proceedings of Annual Conference of Prognostics and Health Management Society 2012, Minneapolis, Minnesota, September 23 - 27, 2012

Doucet, A., Godsill, S., and Andrieu, C., 2000, "On Sequential Monte Carlo Sampling Methods for Bayesian Filtering", Statistics and Computing, Vol. 10, pp. $197-208$.

Doucet, A., Godsill, S., and Andrieu, C., 2000, "On Sequential Monte Carlo Sampling Methods for Bayesian Filtering", Statistics and Computing, Vol. 10, pp. $197-208$.

Durdag, K., 2008, "Solid state acoustic wave sensors for realtime in_line measurement of oil viscosity.", Sensor Review, Vol. 28/1, pp.68-73.

Guan, L., Feng, X.L., Xiong G., and Xie, J.A., 2011, "Application of dielectric spectroscopy for engine lubricating oil degradation. ", Sensors and Actuators A, Vol. 168, pp. 22 - 29

Halderman, J. D., 1996, Automotive Technology, New York: McGraw-Hill.

He, D., Bechhoefer, E., Dempsey, P., and Ma, J., 2012, "An Integrated Approach for Gear Health Prognostics", Proceedings of the 2012 AHS Forum, Fort Worth, TX, April 30 - May 3, 2012.

JJakoby, B., Buskies, M., Scherer, M., Henzler, S., Eisenschmid, H., and Schatz, O., 2001, "Advanced Microsystems for Automotive Applications", Springer, Berlin/Heidelberg/New York, 2001, pp. 157 - 165.

Jakoby B. and Vellekoop, M.J., 2004, "Physical sensors for water-in-oil emulsions." Sensors and Actuators A, Vol. 110 , pp. 28 - 32.

Jakoby, B., Scherer, M., Buskies, M., and Eisenschmid, H., 2002, "Micro viscosity sensor for automobile applications. ", IEEE Sensors, Vol. 2, pp. 1587 - 1590.

Jakoby, B., Scherer, M., Buskies, M., and Eisenschmid, H., 2003, "An automotive engine oil viscosity sensor", IEEE Sensors. J, Vol. 3, pp. $562-568$.

Kittiwake Developments. Ltd. 2011, "Monitoring water in lubricant oil - maintain equipment \& reduce downtime", Critical Things to Monitor, Water in Lube Oil.

Kumar, S., Mukherjee, P. S., and Mishra, N. M., 2005, "Online condition monitoring of engine oil", Industrial Lubrication and Tribology, Vol. 57, No. 6, pp. 260 267.

Merwe, R., Doucet, A., Freitas, N., and Wan E., 2000, "Unscented particle filter", Cambridge University Engineering Department Technical Report cued/finfeng/TR 380.

Orchard M.E. and Vachtsevanos, G.J., 2011, "A Particlefiltering Approach for Online Fault Diagnosis and Failure Prognosis", Transactions of the Institute of Measurement and Control, Vol. 31, pp. 221 - 246.

Poley,J., 2012, "The metamorphosis of oil analysis", Machinery Failure Prevention Technology (MFPT)
Conference, Condition Based Maintenance Section 1, Conference Proceedings, Dayton, Ohio, April $24-26$, 2012.

Raadnui, S. and Kleesuwan, S., 2005, "Low-cost condition monitoring sensor for used oil analysis", Wear, Vol. 259, pp. 1502 - 1506.

Saha, B., Goebel, K., Poll, S., and Christophersen, J., 2009), "Prognostics Methods for Battery Health Monitoring Using a Bayesian Framework", IEEE Transactions on Instrumentation and Measurement, Vol. 58, No. 2, pp. 291-296.

Schmitigal, J. and Moyer, S., 2005, "Evaluation of sensors for on-board diesel oil condition monitoring of U.S. Army ground equipment", TACOM/TARDEC, Report No. 14113.

Sharma, B.C. and Gandhi, O.P., 2008, "Performance evaluation and analysis of lubricating oil using parameter profile approach", Industrial Lubrication and Tribology, Vol. 60, No. 3, pp. 131 - 137.

Stachowiak, G.W. and Batchelor, A.W., 2005, "Physical Property of Lubricants", Engineering Tribology, $3^{\text {rd }}$ edition, pp. 3, ISBN-13: 978-0-7506-7836-0, ISBN-10: 0-7506-7836-4

Turner, J.D. and Austin, L., 2003, "Electrical techniques for monitoring the condition of lubrication oil.", Measurement Science and Technology, Vol. 14, pp. $1794-1800$.

Yoon, J., 2012, "A Comparative Study of Adaptive MCMC Based Particle Filtering Methods", M.S. Thesis, University of Florida

Zio, E. and Peloni, G., 2011, "Particle Filtering Prognostic Estimation of the Remaining Useful Life of Nonlinear Components", Reliability Engineering and System Safety, Vol. 96, pp. 403 - 409.

Zhu, J, He, D., and Bechhoefer, E, 2012, "Survey of lubrication oil condition monitoring, diagnostics, and prognostics techniques and systems", Machine Failure Prevention Technology (MFPT), Conference Proceeding, April 24 - 26, 2012, Dayton, Ohio, USA

Zhu, J, He, D., and Bechhoefer, E, 2013, "Survey of lubrication oil condition monitoring, diagnostics, and prognostics techniques and systems", Journal of Chemical Science and Technology (JCST), (To appear)

\section{BIOGRAPHIES}

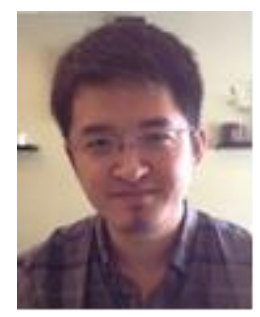

Junda Zhu received his B.S. degree in Mechanical Engineering from Northeastern University, Shenyang, China, and M.S. degree in Mechanical Engineering from The University of Illinois at Chicago in 2009. He is a Ph.D. candidate at the Department of Mechanical and Industrial Engineering. His current research interests include lubrication oil condition monitoring and degradation 
simulation and analysis, rotational machinery health monitoring, diagnosis and prognosis with vibration or acoustic emission based signal processing techniques, physics/data driven based machine failure modeling, CAD and FEA.

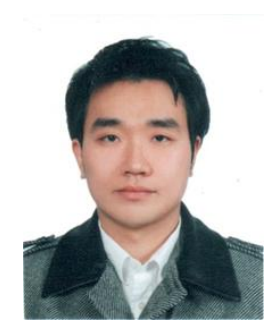

Jae Myung Yoon received his B.E degree in control engineering from Kwangwoon University, Seoul, Republic of Korea, He then worked as an equipment development engineer at the Memory business of Samsung Electronics Co. Ltd from 2006 through 2008. He then received M.S degree in Mechanical and Aerospace engineering from the University of Florida, Gainesville, FL. He is currently pursuing the $\mathrm{Ph} . \mathrm{D}$. degree in industrial engineering with the department of Mechanical and Industrial engineering, University of Illinois at Chicago, Chicago. His current research interests include: machinery health monitoring, diagnostics and prognostics, non-linear filtering, artificial neural networks encompassing reliability engineering.

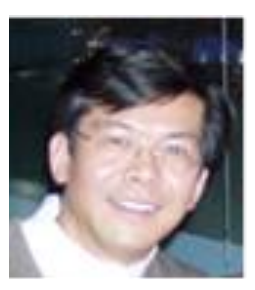

David He received his B.S. degree in Metallurgical Engineering from Shanghai University of Technology, China, MBA degree from The University of Northern Iowa, and Ph.D. degree in Industrial Engineering from The University of Iowa in 1994. Dr. He is a Professor and Director of the Intelligent Systems Modeling \& Development Laboratory in the Department of Mechanical and Industrial Engineering at The University of Illinois-Chicago. Dr. He's research areas include: machinery health monitoring, diagnosis and prognosis, complex systems failure analysis, quality and reliability engineering, and manufacturing systems design, modeling, scheduling and planning.

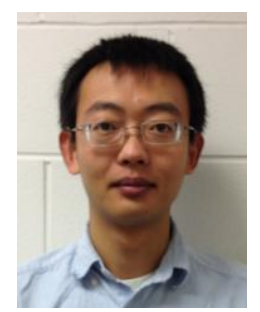

Yongzhi Qu received his B.S. in Measurement and Control and M.S. in Measurement and Testing from Wuhan University of Technology, China. He is a $\mathrm{PhD}$ candidate in the Department of Mechanical and Industrial Engineering at The University of Illinois Chicago. His research interests include: rotational machinery health monitoring and fault diagnosis, especially with acoustic emission sensors, embedded system design and resources allocation and scheduling optimization.

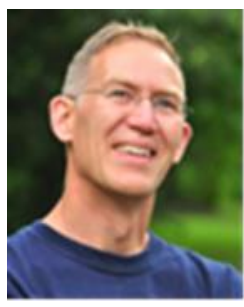

Eric Bechhoefer received his B.S. in Biology from the University of Michigan, his M.S. in Operations Research from the Naval Postgraduate School, and a Ph.D. in General Engineering from Kennedy Western University. His is a former Naval Aviator who has worked extensively on condition based maintenance, rotor track and balance, vibration analysis of rotating machinery and fault detection in electronic systems. Dr. Bechhoefer is a board member of the Prognostics Health Management Society, and a member of the IEEE Reliability Society. 